\title{
Occurrence of spontaneous and audiogenic seizures following global brain ischaemia due to cardiac arrest
}

\author{
Marzena Ułamek-Kozioł ${ }^{1}$, Janusz Kocki ${ }^{2}$, Anna Bogucka-Kocka ${ }^{3}$, Sławomir Januszewski ${ }^{1}$, Stanisław J. Czuczwar ${ }^{4,5}$, \\ Ryszard Pluta ${ }^{1}$ \\ ${ }^{1}$ Laboratory of Ischaemic and Neurodegenerative Brain Research, Mossakowski Medical Research Centre, Polish Academy \\ of Sciences, Warsaw, ${ }^{2}$ Department of Clinical Genetics, Medical University of Lublin, Lublin, ${ }^{3}$ Department of Pharmaceutical \\ Botany, Medical University of Lublin, Lublin, ${ }^{4}$ Department of Pathophysiology, Medical University of Lublin, Lublin, ${ }^{5}$ Department \\ of Physiopathology, Institute of Rural Health, Lublin, Poland
}

\begin{abstract}
Transient cardiac arrest due to cardiac vessel bundle occlusion was used to produce a rat model of spontaneous and audiogenic seizures. Among the rats, spontaneous seizures were present in 64\%, and audiogenic seizures could be evoked in $86 \%$, during two weeks of survival after cardiac arrest, by exposure to a loud sound produced by rattling keys, beginning one day after the post-ischaemic injury. Data from literature suggested a key role for GABA-ergic system widespread dysfunction especially in the hippocampus in post-cardiac arrest onset of audiogenic seizures. Reduced GABA inhibition in the hippocampus seems responsible for audiogenic seizures following cardiac arrest. In summary it may be considered that the occurrence of audiogenic seizures following cardiac arrest is determined not only by a neuronal loss, especially in the hippocampus, but also by a condition of synapse modification by a regenerative phenomenon. Data from our study clearly indicate that global brain ischaemia due to cardiac arrest may induce the susceptibility to spontaneous and audiogenic seizures, but this effect is transient.
\end{abstract}

Key words: cardiac arrest, audiogenic seizures, spontaneous seizures, global brain ischaemia.

\section{Introduction}

Due to the rapid improvement in lifestyle and better of healthcare systems, especially in developed countries, the relative amount of aged people is growing rapidly [12]. With aging, arterial and venous vessel dysfunction occurs, which causes different diseases such as hypertension and/or heart coronary artery disease, which can cause cardiac arrest [3]. Thus, there is the push for a better under- standing of the mechanisms underlying cardiac arrest development and cardiac arrest-related diseases. Cardiac arrest frequently occurs with aging, is a leading cause of death, and plays a crucial role in occurrence of global brain ischaemia and dementia $[3,11,13,29,30]$.

It is reasonable to remark that the brain essentially ages the equivalent of several years within the few minutes taken to resuscitate a patient (or animal) from cardiac arrest. With reference to the natu- 
ral rate of neuronal loss in brain aging, the post-ischaemic brain ages 3.6 years each hour without therapy [27]. In each hour, 120 million neuronal cells, 830 billion synapses, and $714 \mathrm{~km}$ of myelinated fibres are lost [27]. The above abnormalities can be part of the cause of the death of ischaemia-susceptible neurons in areas such as the hippocampus and dysfunction of other, e.g. cortical, neurons also contributing to dysfunction of the neural network. Secondary pathology in the hippocampus in humans and after experimental global cerebral ischaemia due to cardiac arrest occurs with several features similar to Alzheimer's disease $[10,20,21,23,24]$. The most important similarity is the accumulation of amyloid precursor protein or its fragments, e.g. $\beta$-amyloid peptide, in intra- and extracellular space in the hippocampus in humans and rats subjected to transient global brain ischaemia $[10,20,26]$. The progression of neuronal impairment and cell death, observed during cardiac arrest and following post-arrest, is very fast; however, processes involved in progression are unknown fully. A wide variety of brain lesions and injuries are associated with increased risk for development of seizures. The biggest risk factor are cerebrovascular pathologies, at around 21\% [4]. Post-ischaemic acute symptomatic seizures occur at between 3 and 15\% (c. $11 \%)$, more commonly in animals and humans with severe brain injury [4]. Seizures, especially after cardiac arrest, are of increasing importance as the population ages and are a growing contribution to symptomatic epilepsies. Post-cardiac arrest seizures are less well characterised and are good targets for clinical trials of seizure prevention. Despite differences between humans and animals, and the time courses, mechanistic information gained from studying the experimental cardiac arrest conditions could be harnessed to synergistically advance both groups and to develop treatments targeting specific components in these neurodegenerative pathways to provide more robust protection of patients from neurocognitive impairment and/or death [29]. However, little is known about cardiac arrest-related diseases or induced brain dysfunction resulting because of the occurrence of seizures.

Experimental data indicate that cardiac arrest induces a susceptibility to audiogenic seizures in previously unsusceptible rats [7]. In view of the importance of cardiac arrest in human and its increasing occurrence in the world, as well as its frequent association with seizures, an experimental cardiac arrest model was used in the present investigations. Consequently, the present study was aimed at elucidating whether cardiac arrest in rats could induce audiogenic seizure susceptibility in Wistar rats that were not susceptible to audiogenic stimulation.

\section{Material and methods}

The cardiac arrest was induced by a method described previously by Pluta et al. [16]. Female Wistar rats were used (150-170 g, 3 months old). In animals under anaesthesia [7], a blunt-ended, hooklike, metal probe with the distal end bent at $90^{\circ}$ was placed inside the rats' chest cavity after midline skin incision [16]. The hook was inserted through the right parasternal line and third intercostal space into the mediastinum. The hook was gently positioned under the heart vessel bundle and was then moved up and, at the same time, finger pressure (index and middle) was applied from outside. Blood flow in both arterial and venous heart blood vessels was stopped. The device was removed after 3.5 minutes. The animals remained in a state similar to clinical death for 10 minutes. Next the resuscitation procedure was initiated with external heart massage and artificial ventilation with room air (7025 Rodent Ventilator, Ugo Basile, Italy). The procedure was continued until spontaneous heart activity and respiration were resumed. After cardiac arrest the rats $(n=50)$ survived for one month. Audiogenic seizures were triggered by using the rattling sound of keys (sound intensity 90-100 dB, frequency $>4,000 \mathrm{~Hz}$ ), according to Kawai et al. [7]. The sound stimulus was set until rats started to have seizures. Audiogenic seizure test was performed 24 hours after cardiac arrest, once daily for one month. The rats were kept in plastic cages with free access to food and tap water under standardised housing conditions (natural light/dark cycle, temperature of $24 \pm 2^{\circ} \mathrm{C}$, relative humidity $55 \pm 5 \%)$. Procedures involving animals and their care were conducted in accordance with the guide for the care and use of laboratory animals as adopted and promulgated by the National Institutes of Health. The experimental protocols and procedures described here were approved by the First Local Ethical Committee in Warsaw.

\section{Results}

Following 10 minutes of cardiac arrest, spontaneous heart activity was restored after $82.7 \pm 16.5$ 
seconds (mean \pm SD) and respiratory activity within $8.4 \pm 1.3$ minutes. The pain reaction reappeared at $15.8 \pm 3.0$ minutes and the corneal reflex at 28.5 \pm 4.3 minutes following cardiac arrest. After reanimation procedure taking about one hour the rats were placed onto one side of a cage. After 24 hours the animals resumed a normal posture without paralysis of legs. Following that, the animals began to feed themselves and became restless. All animals after 10-minute cardiac arrest were alert and had no motor deficits at one day of survival, which is in accordance with other data $[7,8]$. As already shown, the rats' survival up to one month after reanimation did not exhibit any neurological or somatic deficits during the whole period of observation [8]. After successful resuscitation, during a one-month period all of the animals survived following cardiac arrest.

Animals after cardiac arrest showed spontaneous (64\% [ $n=32$ out of 50]) and induced (by rattling keys) audiogenic ( $86 \%$ [ $n=43$ out of 50$]$ ) susceptibility to seizures with manifestation of the behaviours presented below. The spontaneous sensitivity and induced-by-rattling-key audiogenic seizures became manifest on the first day following reanimation, just after the animals had resumed their normal posture. At that time the animals appeared to be hyperreactive. Spontaneous and sound-triggered seizures started with an episode of locomotor automatism and vocalisation. They always reacted with bouncing or jumping (startle myoclonus) when one loud rattling key stimulation was given. After a few seconds, the rats suddenly started instantaneous and wild continuous running without any attempts to avoid obstacles and/or directional change. The running was completely uncontrolled. The animals bumped into the wall of the cage and/or its cover. With the end of this furious running, the animals presented brief tonic extension of the trunk and all four limbs; this was followed by clonic movements - bouncing or jumping, involving the whole body. At the end of the above episode, the rats tended to fall onto one side and the clonic movements suddenly disappeared. After that, postictal irritability was observed, e.g. for touch as effect they started again running, jumping with vocalisation. Finally, all of the rats had postictal depression characterised by a catatonic posture and immobility. This state of activity lasted from a few to several seconds. The occurrence of spontaneous and audiogenic seizures was observed only for a period of two weeks, following cardiac arrest. The sham-op- erated rats ( $n=5$; with surgery but without the cardiac arrest) were also observed for one month for the possible occurrence of seizure activity. However, neither spontaneous nor audiogenic seizure activity was noted.

\section{Discussion}

Seizures following transient global brain ischaemia due to cardiac arrest are of increasing importance as the population ages, and may be considered as a growing contribution to symptomatic epilepsies. An association of acute brain ischaemia due to cardiac arrest with seizures has been regarded as indicator of severe ischaemic brain injury. In clinical conditions, the appearance of seizures following cardiac arrest seems a predictor of poor outcome [9,29]. In our study, regular onset of audiogenic seizures was noted one day after cardiac arrest, which is in accordance with the observations by Kawai et al. [7]. In our model, audiogenic seizures occured in the first two weeks of survival after acute transient global brain ischaemia, and after a particular period of time completely disappeared.

Available evidence indicates that one of the consequences of cardiac arrest in humans may be seizure activity or myoclonic status epilepticus [2]. Generally, the prognosis for resuscitated patients seems to be poor and only a small proportion of them recover without serious neurological deficits [2]. The pathogenesic pathways are incompletely understood, but they may include alterations in the energy metabolism [4] and blood-brain barrier functioning [17,25], intracellular $\mathrm{Ca}^{2+}$ overload [15], release of excitotoxic glutamate [15], neuroinflammation [28], free radical changes [23], and the presence of brain parenchyma haemorrhages [14]. Kawai et al. [5] observed remarkable neuronal changes, affecting predominantly GABA-ergic neurons in different areas, immediately following cardiac arrest. Observations by Kawai et al. [7] suggested a key role for GABA-ergic system widespread dysfunction especially in the hippocampus in post-cardiac arrest onset of audiogenic seizures. $A$ reduced GABA inhibition in the hippocampus seems responsible for audiogenic seizures following cardiac arrest. However, data are available, showing that GABA-egric deficit seems largely reversible as a sign of some plastic modifications/regenerations such as sprouting of inhibitory terminals from surviving interneurons [7]. According to previous inves- 
tigations, regenerative sprouting of GABA-ergic terminals coincides with cessation of the appearance of audiogenic seizures following cardiac arrest [6]. Interestingly, animals after global brain ischaemia lasting in the range of five minutes did not develop any susceptibility to audiogenic stimulation [7]. When the mean duration of ischaemia reached circa nine minutes, which is slightly less than our experimental conditions, $65 \%$ of rats responded with audiogenic seizures [7]. Our recent data also indicate that cardiac arrest rats show an increased susceptibility to pentylenetetrazol-induced clonic seizure activity after one month but not after two months, and this effect is probably also associated with a transient deficit in central GABA-ergic neurotransmission [1].

Two days after cardiac arrest, small areas of neuronal disappearance were noted in the selectively vulnerable hippocampus CA1 region $[18,20,21]$. At 7-14 days, in ischaemic hippocampus neuronal loss was almost complete in CA1 area with single and scattered damaged pyramidal neurons $[8,18,20,21]$. But in areas not selectively vulnerable, such as CA2, CA3, and CA4 sectors of the hippocampus, alterations were of a nature characteristic of the acute ischaemic phase [20-22]. In different periods following ischaemia, regions of neuronal loss were replaced by proliferating and hypertrophic astrocytes with staining for $\beta$-amyloid peptide and microglia $[18,19]$. The above pathology was localised in layers 3, 5, and 6 of the neocortex and the striatum. The ischaemic neuronal changes are identified as progressive acute and chronic degeneration processes of neuronal cells in the brain, taking place during the whole period of recirculation. Recently it has been identified that degenerative machinery in post-ischaemic neuronal cells continues outside the acute period of the ischaemic episode [18-20]. Evidence indicates that post-ischaemic brain injury, regardless of the time of survival after ischaemia, is followed by acute neuronal damage as a "burning phenomenon" in areas of the brain belonging or not to selectively vulnerable regions [18-22].

In summary, it may be considered that the occurrence of audiogenic seizures following cardiac arrest is determined not only by neuronal loss, especially in the hippocampus, but also by a condition of synapse modification by regenerative phenomenon. Data from our study clearly indicate that global brain ischaemia due to cardiac arrest may trigger suscep- tibility to spontaneous and audiogenic seizures, but this effect is transient.

\section{Acknowledgments}

The authors acknowledge the support of the Polish National Science Centre (DEC-2013/09/B/ NZ7/01345-RP,MUK,SJ,ABK,SJC,JK) and the Mossakowski Medical Research Centre, Polish Academy of Sciences, Poland (T3-RP). Also, this study was supported by a grant from the Medical University of Lublin, Poland (DS 475-SJC). The paper was developed using the equipment purchased within the Project "The equipment of innovative laboratories doing research on new medicines used in the therapy of civilisation and neoplastic diseases" within the Operation Program Development of Eastern Poland 2007-2013, Priority Axis I Modern Economy, Operations I.3 Innovation Promotion (JK,SJC).

\section{Disclosure}

Authors report no conflict of interest.

\section{References}

1. Dudra-Jastrzebska M, Ułamek-Kozioł $M$, Andres-Mach $M$, Luszczki JJ, Januszewski S, Czuczwar SJ, Pluta R. Seizure susceptibility to electroconvulsions or pentylenetetrazol after complete cerebral ischaemia in rats due to cardiac arrest. Pharmacol Rep 2015; 67: 417-420.

2. Geri G, Mongardon N, Daviaud F, Empana JP, Dumas F, Cariou A. Neurological consequences of cardiac arrest: Where do we stand? Ann Fr Anesth Reanim 2014; 33: 98-101.

3. Go AS, Mozaffarian D, Roger VL, Benjamin EJ, Berry JD, Blaha MJ, Dai S, Ford ES, Fox CS, Franco S, Fullerton HJ, Gillespie C, Hailpern SM, Heit JA, Howard VJ, Huffman MD, Judd SE, Kissela BM, Kittner SJ, Lackland DT, Lichtman JH, Lisabeth LD, Mackey RH, Magid DJ, Marcus GM, Marelli A, Matchar DB, McGuire DK, Mohler ER 3rd, Moy CS, Mussolino ME, Neumar RW, Nichol G, Pandey DK, Paynter NP, Reeves MJ, Sorlie PD, Stein J, Towfighi A, Turan TN, Virani SS, Wong ND, Woo D, Turner MB. Heart disease and stroke statistics - 2014 update: a report from the American Heart Association. Circulation 2014; 129: e28-e292.

4. Herman ST. Epilepsy after brain insult. Targeting epileptogenesis. Neurology 2002; 59 (Suppl 5): S21-S26.

5. Kawai K, Nitecka L, Reutzler CA, Nagashima G, Joó F, Mies G, Nowak TS, Saito N, Lohr JM, Klatzo I. Global cerebral ischaemia associated with cardiac arrest in the rat: I. Dynamics of early neuronal changes J Cereb Blood Flow Metab 1992; 12: 238-249.

6. Kawai K, Penix LP, Ruetzler CA, Nitecka L, Lohr JM, Klatzo I. Effect of cardiac arrest cerebral ischaemia on the GABA-ergic system and development of audiogenic seizures. In: Pharmacology of Cerebral Ischaemia. Krieglstein J, Oberpichler-Schwenk H (eds.). Wissenschaftliche Verlaggesellschaft, Stuttgart 1992; pp. 195-206. 
7. Kawai K, Penix LP, Kawahara N, Ruetzler CA, Klatzo I. Development of susceptibility to audiogenic seizures following cardiac arrest cerebral ischaemia in rats. J Cereb Blood Flow Metab 1995; 15: 248-258.

8. Kiryk A, Pluta R, Figiel I, Mikosz M, Ułamek M, Niewiadomska G, Jabłoński M, Kaczmarek L. Transient brain ischaemia due to cardiac arrest causes irreversible long-lasting cognitive injury. Behav Brain Res 2011; 219: 1-7.

9. Krumholz A, Stern BJ, Weiss HD. Outcome from coma after cardiopulmonary resuscitation: relation to seizures and myoclonus. Neurology 1988; 38: 401-405.

10. Maślińska D, Laure-Kamionowska M, Taraszewska A, Deręgowski K, Maśliński S. Immunodistribution of amyloid beta protein $(A \beta)$ and advanced glycation end-product receptors (RAGE) in choroid plexus and ependyma of resuscitated patients. Folia Neuropathol 2011; 49: 295-300.

11. Moulaert VRMP, Verbunt JA, van Heugten CM, Wade DT. Cognitive impairments in survivors of out-of-hospital cardiac arrest: A systematic review. Resuscitation 2009; 80: 297-305.

12. North BJ, Sinclair DA. The intersection between aging and cardiovascular disease. Circ Res 2012; 110: 1097-1108.

13. O'Reilly SM, Grubb NR, O'Carroll RE. In-hospital cardiac arrest leads to chronic memory impairment. Resuscitation 2003; 58 73-79.

14. Pluta R. Influence of prostacyclin on early morphological changes in the rabbit brain after complete 20-min ischaemia. J Neurol Sci 1985; 70: 305-316.

15. Pluta R, Salińska E, Puka M, Stafiej A, Łazarewicz JW. Early changes in extracellular amino acids and calcium concentrations in rabbit hippocampus following complete 15-min cerebral ischaemia. Resuscitation 1988; 16: 193-210.

16. Pluta R, Lossinsky AS, Mossakowski MJ, Faso L, Wiśniewski HM. Reassessment of new model of complete cerebral ischaemia in rats. Method of induction of clinical death, pathophysiology and cerebrovascular pathology. Acta Neuropathol 1991; 83: 1-11.

17. Pluta R, Lossinsky AS, Wiśniewski HM, Mossakowski MJ. Early blood-brain barrier changes in the rat following transient complete cerebral ischaemia induced by cardiac arrest. Brain Res 1994; 633: 41-52.

18. Pluta R. The role of apolipoprotein $E$ in the deposition of beta-amyloid peptide during ischaemia-reperfusion brain injury. A model of early Alzheimer's disease. Ann NY Acad Sci 2000; 903: 324-334.

19. Pluta R. Glial expression of the $\beta$-amyloid peptide in cardiac arrest. J Neurol Sci 2002; 203-204: 277-280.

20. Pluta R, Ułamek M, Jabłoński M. Alzheimer’s mechanisms in ischaemic brain degeneration. Anat Rec 2009; 292: 1863-1881.

21. Pluta R, Ułamek-Kozioł M, Januszewski S, Ściślewska M, Boguc ka-Kocka A, Kocki J. Alzheimer's factors in postischaemic dementia. Rom J Morphol Embryol 2012; 53: 461-466.

22. Pluta R, Jabłoński M, Czuczwar SJ. Postischaemic dementia with Alzheimer phenotype: selectively vulnerable versus resistant areas of the brain and neurodegeneration versus $\beta$-amyloid peptide. Folia Neuropathol 2012; 50: 101-109.

23. Pluta R, Furmaga-Jabłońska W, Maciejewski R, Ułamek-Kozioł M Jabłoński M. Brain ischaemia activates $\beta$ - and $\gamma$-secretase clea- vage of amyloid precursor protein: significance in sporadic Alzheimer's disease. Mol Neurobiol 2013; 47: 425-434.

24. Pluta R, Jabłoński M, Ułamek-Kozioł M, Kocki J, Brzozowska J, Januszewski S, Furmana- Jabłońska W, Bogucka-Kocka A, Maciejewski R, Czuczwar SJ. Sporadic Alzheimer's disease begins as episodes of brain ischaemia and ischaemically dysregulated Alzheimer's disease genes. Mol Neurobiol 2013; 48: 500-515.

25. Preston E, Sutherland G, Finsten A. Three openings of the blood-brain barrier produced by forebrain ischaemia in the rat. Neurosci Lett 1993; 149: 75-78.

26. Qi J, Wu H, Yang Y, Wand D, Chen Y, Gu Y, Liu T. Cerebral ischaemia and Alzheimer's disease: The expression of amyloid- $\beta$ and apolipoprotein $\mathrm{E}$ in human hippocampus. J Alzheimer's Dis 2007; 12: 335-341.

27. Saver JL. Time is brain-quantified. Stroke 2006; 37: 263-266.

28. Sekeljic V, Bataveljic D, Stamenkovic S, Ułamek M, Jabłoński M, Radenovic L, Pluta R, Andjus PR. Cellular markers of neuroinflammation and neurogenesis after ischaemic brain injury in the long-term survival rat model. Brain Struct Funct 2012; 217: 411-420.

29. Wijdicks EF, Parisi JE, Sharbrough FW. Prognostic value of myoclonic status in comatose survivors of cardiac arrest. Ann Neurol 1994; 35: 239-243.

30. Young GB. Clinical practice. Neurologic prognosis after cardiac arrest. N Engl J Med 2009; 361: 605-611. 